\title{
AXIOMATIC DESAIN KOTAK OBAT UNTUK TUNA NETRA
}

\author{
${ }^{1}$ Widyastuti, ${ }^{2}$ Ida Betanursanti \\ ${ }^{1,2}$ Program Studi Teknik Industri, Sekolah Tinggi Teknologi Muhammadiyah Kebumen \\ Jl. Indrakila No. 38 A Kebumen \\ e-mail: ibetanursanti@gmail.com
}

\begin{abstract}
Abstrak
Aktifitas mengkonsumsi obat secara mandiri bagi tuna netra bukanlah hal yang mudah. Kesulitan yang mereka hadapi diantaranya adalah dalam hal membedakan jenis obat. Inovasi desain kotak obat diperlukan agar tuna netra dapat mengambil jenis obat secara mandiri dan aman. Pada penelitian ini dilakukan perancangan kotak obat dengan menggunakan metode axiomatic. Proses desain diawali dengan identifikasi customer atribut (CA) dari tuna netra kemudian dipetakan menjadi functional requirements (FR) untuk menghasilkan desain parameter (DP). Tahapan selanjutnya adalah pembuatan prototype yang divalidasi menggunakan uji statistik marginal homogeneity Stuart Maxwell. Hasil pengujian menunjukkan bahwa desain yang dibuat dapat memenuhi kriteria yang dibutuhkan oleh pengguna.
\end{abstract}

Kata kunci : Kotak Obat, Axiomatic Desain, Tuna Netra

\section{PENDAHULUAN}

Kesehatan merupakan kebutuhan dasar bagi setiap orang. Salah satu upaya untuk menjaga dan mengembalikan kondisi tubuh agar tetap sehat adalah dengan mengkonsumsi obat (Fuente dan Bix, 2010). Bagi orang normal mengkonsumsi obat merupakan aktifitas yang mudah, namun bagi penyandang tuna netra tidaklah demikian. Ketika mereka melakukannya secara mandiri keterbatasan pengelihatan mengakibatkan kesulitan dalam mencari lokasi obat, membedakan jenis obat, mengidentifikasi kegunaan obat, mengidentifikasi dosis, dan mengingat petunjuk penggunaan obat (Weeraranthe dan Opatha, 2012). Kotak obat yang tersedia saat ini pada umumnya belum mengakomodasi kebutuhan tuna netra. Oleh karena itu diperlukan inovasi desain kotak obat agar mereka dapat mandiri mengkonsumsi obat secara aman.

Salah satu metode desain yang sistematis, logis dan rasional untuk mendesain sebuah produk adalah axiomatic desain (AD)(Suh, 2001). Proses perancangan dilakukan berdasarkan customer atribut (CA) yang kemudian dipetakan menjadi functional requirements (FR) sehingga menghasilkan desain parameter (DP) dengan menggunakan proses zigzag (El-Haik dan Suh, 2005). Beberapa produk telah dihasilkan dengan AD, diantaranya in-pipe robot (Qiao dan Shang, 2013), model novel circuit (Ferent dan Doboli, 2013), dermaga galangan kapal (Celik dan Kahraman, 2009), dan desain lingkungan virtual yang ergonomis (Taha dkk, 2014). Berdasarkan hal tersebut maka dalam penelitian ini desain kotak obat untuk tuna netra dibuat menggunakan pendekatan metode axiomatic desain. Sasaran utama perancangan adalah untuk mengatasi kesulitan tuna netra dalam membedakan jenis obat.

\section{METODE PENELITIAN}

Penelitian dilaksanakan berdasarkan pendekatan metode axiomatic untuk menentukan desain parameter kotak obat. Tahapan penelitian terdiri dari identifikasi CA, pemetaan CA menjadi FR dan DP, pembuatan prototype dan pengujian prototype.

\section{A. Survey}

Survey dilakukan menggunakan kuisioner dengan responden penyandang tuna netra. Proses ini terdiri atas dua tahapan yaitu survey identifikasi CA dan pengujian prototype.

\section{B. Analisis statistik}

Analisis statistik nonparametrik diterapkan dalam pengujian validitas dan reliabilitas CA dengan menggunakan Cronbach Alpha dan korelasi Spearman (Sheskin, 2006). CA yang teridentifikasi selanjutnya dikelompokkan menggunakan analisis faktor. Pada tahap 
terakhir, hasil pengujian prototype dianalisis menggunakan uji statistik marginal homogeneity Stuart Maxwell (Sheskin, 2006).

\section{HASIL DAN PEMBAHASAN}

\section{A. Customer Atribut (CA)}

Customer atribut ditentukan berdasarkan hasil survey terhadap tuna netra sehingga diperoleh 5 CA yang valid dan reliable. Kelima CA tersebut selanjutnya dikelompokkan menggunakan analisis factor menggunakan metode principal factor dan varimax rotation sehingga diperoleh dua kelompok yang masing-masing diwakili dengan dua axiom seperti dijelaskan pada tabel berikut:

Tabel 1. Pengelompokan customer atribut (CA)

\begin{tabular}{ll}
\hline \multicolumn{1}{c}{ CA 1 (Aman) } & \multicolumn{1}{c}{ CA 2 (Praktis) } \\
\hline Tidak membahayakan & Mudah dipakai \\
Obat tidak rusak & Mudah dicari \\
Tidak mudah pecah & \\
\hline
\end{tabular}

\section{B. Desain Parameter (DP)}

Kedua CA yang telah diperoleh selanjutnya dipetakan menjadi FR dan DP seperti tercantum pada tabel 2 dan tabel 3 berikut :

Tabel 4.2 Pemetaan kotak obat yang aman

\begin{tabular}{|c|c|c|c|c|c|}
\hline Kode & CA & Kode & FR & Kode & DP \\
\hline \multirow{4}{*}{ CA 1} & \multirow{4}{*}{ Aman } & FR 1 & $\begin{array}{l}\text { Merancang kotak } \\
\text { obat yang tidak } \\
\text { membahayakan } \\
\text { pengguna dan tidak } \\
\text { mengkontaminasi } \\
\text { obat }\end{array}$ & DP 1 & Desain fisik kotak obat \\
\hline & & FR 1.1 & $\begin{array}{l}\text { Merancang ruangan } \\
\text { kotak obat }\end{array}$ & DP 1.1 & $\begin{array}{l}\text { - } 1 \text { ruang perangkat } \\
\text { sistem otomatisasi } \\
\text { - } 3 \text { rak bertingkat } \\
\text { penyimpan obat luar, } \\
\text { obat tablet, obat sirup }\end{array}$ \\
\hline & & FR 1.2 & $\begin{array}{l}\text { Menentukan bahan } \\
\text { kotak obat }\end{array}$ & DP 1.2 & $\begin{array}{l}\text { Bahan kotak luar : triplek } \\
\text { melamin dan kayu } \\
\text { Bahan penyimpan obat : } \\
\text { Plastik polypropylene }\end{array}$ \\
\hline & & FR 1.3 & $\begin{array}{l}\text { Menentukan ukuran } \\
\text { kotak obat }\end{array}$ & DP 1.3 & $\begin{array}{l}\text { Ukuran total: } 50 \mathrm{~cm} \times 30 \mathrm{~cm} \\
\text { x } 40 \mathrm{~cm} \\
\text { Ruang sistem otomatisasi : } \\
30 \mathrm{~cm} \text { x } 30 \mathrm{~cm} \times 40 \mathrm{~cm} \\
\text { Ruang total tempat obat : } \\
20 \mathrm{~cm} \text { x } 30 \mathrm{~cm} \times 40 \mathrm{~cm} \\
\text { Rak atas: } 20 \times \mathrm{xm} \times 30 \mathrm{~cm} \times \\
10 \mathrm{~cm} \\
\text { Rak tengah: } 20 \mathrm{xm} \times 30 \mathrm{~cm} \\
\text { x } 10 \mathrm{~cm} \\
\text { Rak bawah: } 20 \mathrm{~cm} \times 30 \mathrm{~cm} \times \\
20 \mathrm{~cm}\end{array}$ \\
\hline
\end{tabular}


Tabel 3. Pemetaan CA praktis

\begin{tabular}{|c|c|c|c|c|c|}
\hline Kode & $\mathrm{CA}$ & Kode & FR & Kode & DP \\
\hline \multirow{4}{*}{ CA 2} & \multirow{4}{*}{ Praktis } & FR 2 & $\begin{array}{lr}\text { Merancang } & \text { kotak } \\
\text { obat yang mudah } \\
\text { dioperasikan dan } \\
\text { memberikan dampak } \\
\text { psikologi positif }\end{array}$ & DP 2 & Desain fungsional kotak obat \\
\hline & & FR 2.1 & $\begin{array}{l}\text { Menetukan fungsi } \\
\text { otomatisasi pembuka } \\
\text { rak kotak obat }\end{array}$ & DP 2.1 & 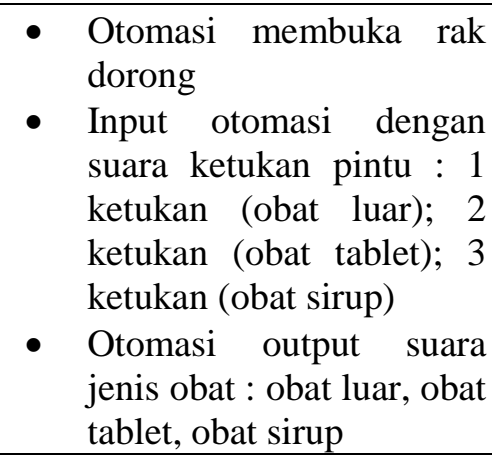 \\
\hline & & FR 2.2 & $\begin{array}{l}\text { Membuat } \\
\text { otomatisasi }\end{array}$ & DP 2.2 & $\begin{array}{l}\text { Perangkat sistem otomatisasi: } \\
\text { - Sensor unit } \\
\text { - } \quad \text { Modul microcontroller } \\
\text { arduino } \\
\text { - Speaker } \\
\text { - } \quad \text { Actuator switch selenoid } \\
\text { - } \quad \text { Power supply } 3 \text { Ampere } \\
\quad 12 \text { volt } \\
\end{array}$ \\
\hline & & FR 2.3 & $\begin{array}{l}\text { Membuat ciri khusus } \\
\text { penanda pintu kotak } \\
\text { obat }\end{array}$ & DP 2.3 & 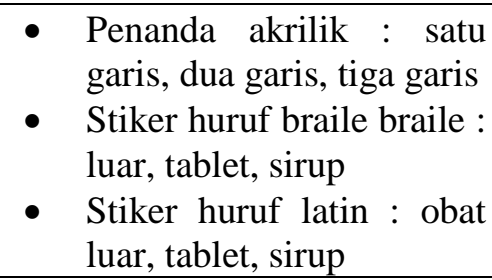 \\
\hline
\end{tabular}

Proses pemetaan tersebut secara sistematis digambarkan dalam struktur hierarki di bawah ini :

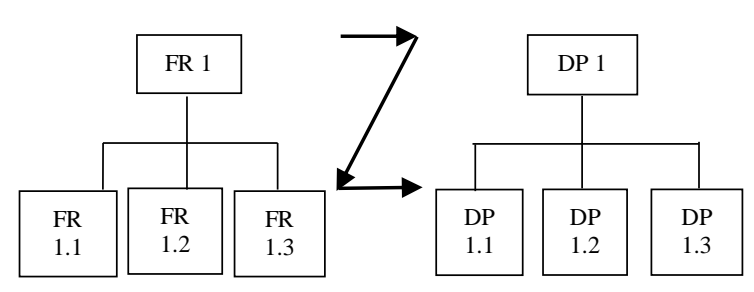

Gambar 2a. Sruktur hierarki pemetaan CA Aman

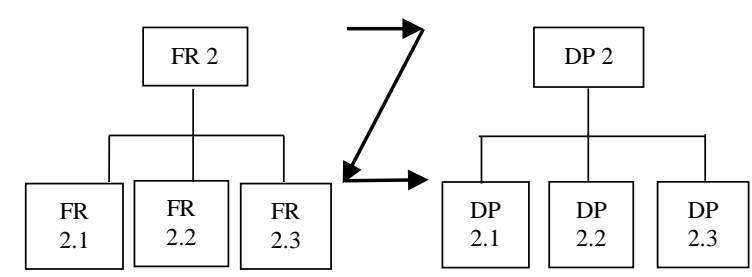

Gambar 2b. Sruktur hierarki pemetaan CA Praktis

Hubungan antar axiom FR dan DP dalam desain ini merupakan matrik uncoupled pada pemetaan CA1 dan matrik decoupled pada pemetaan CA2 seperti dijabarkan dalam matrik berikut :

$\left[\begin{array}{ll}F R & 1.1 \\ F R & 1.2 \\ F R & 1.3\end{array}\right]=\left\{\begin{array}{lll}1 & 0 & 0 \\ 0 & 1 & 0 \\ 0 & 0 & 1\end{array}\right\}\left[\begin{array}{ll}D P & 1.1 \\ D P & 1.2 \\ D P & 1.3\end{array}\right]$

Gambar 3a. matrik pemetaan CA1
$\left[\begin{array}{ll}F R & 2.1 \\ F R & 2.2 \\ F R & 2.3\end{array}\right]=\left\{\begin{array}{lll}1 & 0 & 0 \\ 1 & 1 & 0 \\ 0 & 0 & 1\end{array}\right\}\left[\begin{array}{ll}D P & 2.1 \\ D P & 2.2 \\ D P & 2.3\end{array}\right]$

Gambar 3a. matrik pemetaan CA2 


\section{Desain Usulan}

Berdasarkan desain parameter di atas, selanjutnya dibuat prototype. Kotak obat berukuran total $50 \mathrm{~cm} \times 30 \mathrm{~cm}$ x $40 \mathrm{~cm}$ (gambar 4) yang terdiri dari ruang sistem otomasi dan ruang obat. Ruang obat terdiri dari tiga rak bersusun dengan ukuran masing - masing tertera pada gambar 5 .
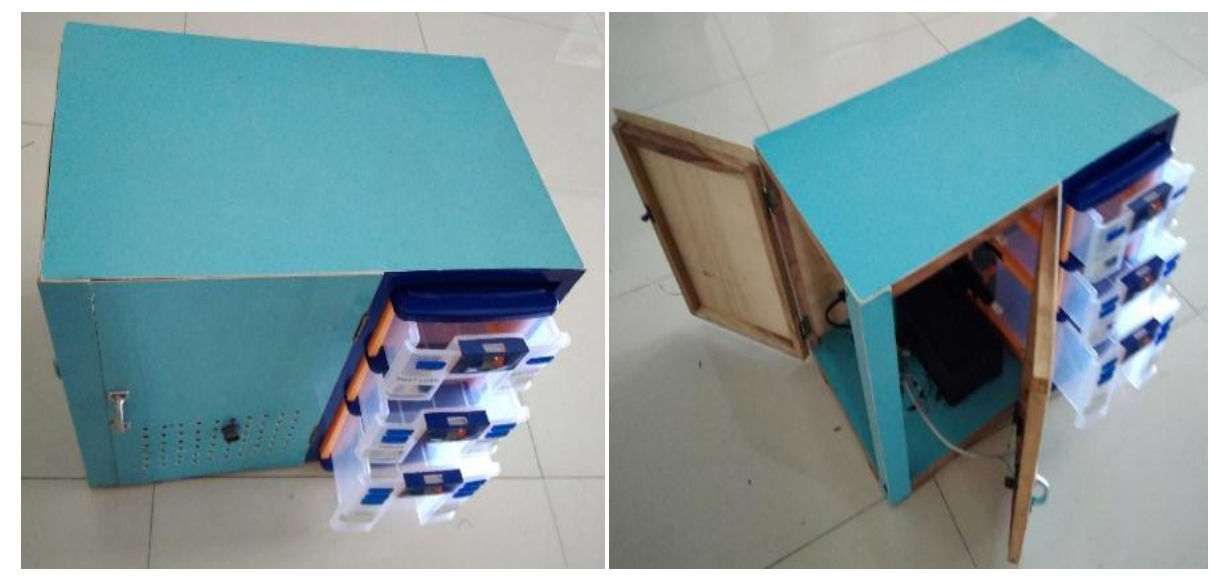

Keterangan :

Ukuran total

Panjang $=50 \mathrm{~cm}$

Lebar $=30 \mathrm{~cm}$

Tinggi $=40 \mathrm{~cm}$

Gambar 4. Kotak obat tampak keseluruhan

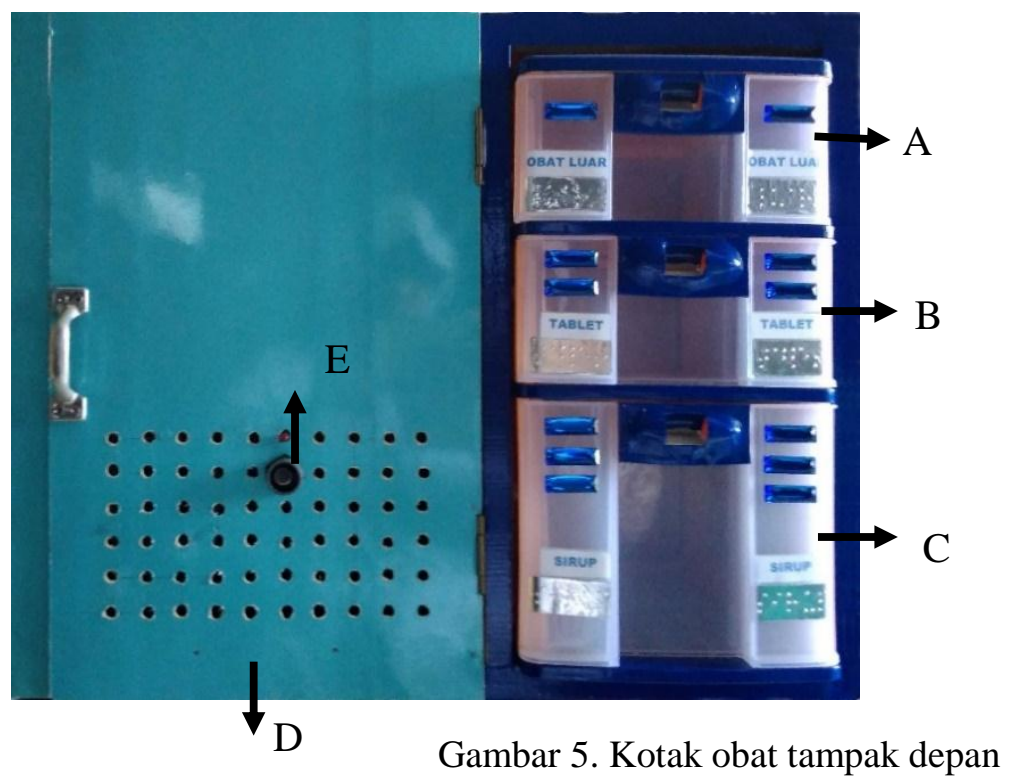

Keterangan :

$\mathrm{A}=$ rak obat luar

$(20 \mathrm{xm} \times 30 \mathrm{~cm} \times 10 \mathrm{~cm})$

$\mathrm{B}=$ rak obat tablet

$(20 \mathrm{xm} \times 30 \mathrm{~cm} \times 10 \mathrm{~cm})$

$\mathrm{C}=$ rak obat sirup

$(20 \mathrm{~cm} \times 30 \mathrm{~cm} \times 20 \mathrm{~cm})$

$\mathrm{D}=$ Ruang sistem

otomatisasi

$(30 \mathrm{~cm} \times 30 \mathrm{~cm} \times 40 \mathrm{~cm}$ )

$\mathrm{E}=$ sensor suara

Sistem otomatisasi kotak obat berupa otomatisasi pembuka pintu yang dijalankan dengan menggunakan tenaga listrik. Jika listrik mati kotak obat tetap dapat dibuka, pengguna membedakan jenis obat dengan cara manual berdasarkan petunjuk yang tertera di luar pintu. Petunjuk terdiri dari pananda akrilik, stiker huruf braile dan stiker huruf latin (gambar 6). 


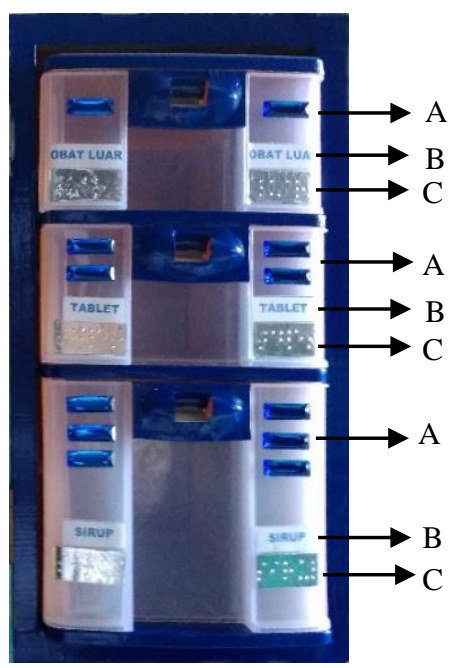

Keterangan :

$\mathrm{A}=$ penanda akrilik

$\mathrm{B}=$ stiker huruf latin

$\mathrm{C}=$ stiker huruf braile

Gambar 6. Gambar penanada pintu kotak obat

Rangkaian sistem terdiri dari rangkaian sensor suara, modul microcontroller, power supply, actuator switch solenoid, dan speaker (gambar 7).

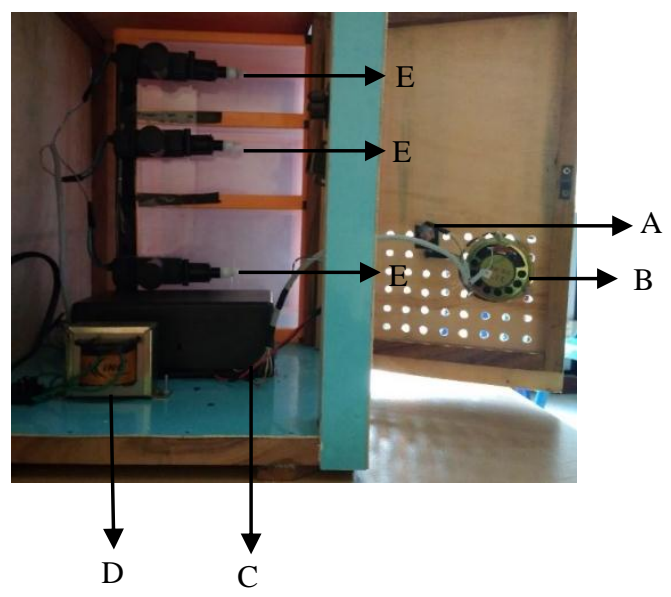

$$
\begin{aligned}
& \text { Keterangan }: \\
& A=\text { sensor unit } \\
& B=\text { speaker } \\
& C=\text { modul microcontroller } \\
& D=\text { power supply } \\
& E=\text { actuator } \text { switch selenoid }
\end{aligned}
$$

Gambar 7. Rangkaian otomatisasi kotak obat

Modul microcontroller diprogram menggunakan bahasa perograman untuk microcontroller arduino agar pintu dapat membuka sendiri sesuai dengan perintah, diiringi suara yang menunjukkan jenis obat. Perintah membuka pintu dilakukan dengan mengetuk pintu kayu. Satu ketukan untuk obat luar (rak paling atas), dua ketukan untuk obat tablet (rak tengah) dan tiga ketukan untuk obat sirup (rak paling bawah) seperti dijelaskan pada gambar 8 . Setelah obat diambil, pintu ditutup secara manual.

\section{Validasi Desain Kotak Obat}

Uji Marginal homogeneity Stuart Maxwell diterapkan untuk memvalidasi desain kotak obat. Pengujian dilakukan berdasarkan hipotesis sebagai berikut :

Ho : Tidak ada perbedaan yang signifikan antara customer atribut (kebutuhan pengguna) dan desain kotak obat

$\mathrm{H}_{1}$ : Ada perbedaan yang signifikan antara customer atribut (kebutuhan pengguna) dan desain kotak obat 
Hasil uji menunjukkan bahwa nilai z untuk aman $=0,705$ dan nilai z untuk praktis $=0,480$. Karena $\mathrm{z}>0,005$ maka Ho dapat diterima yang bermakna bahwa desain kotak obat yang dibuat dapat memenuhi kebutuhan pengguna.

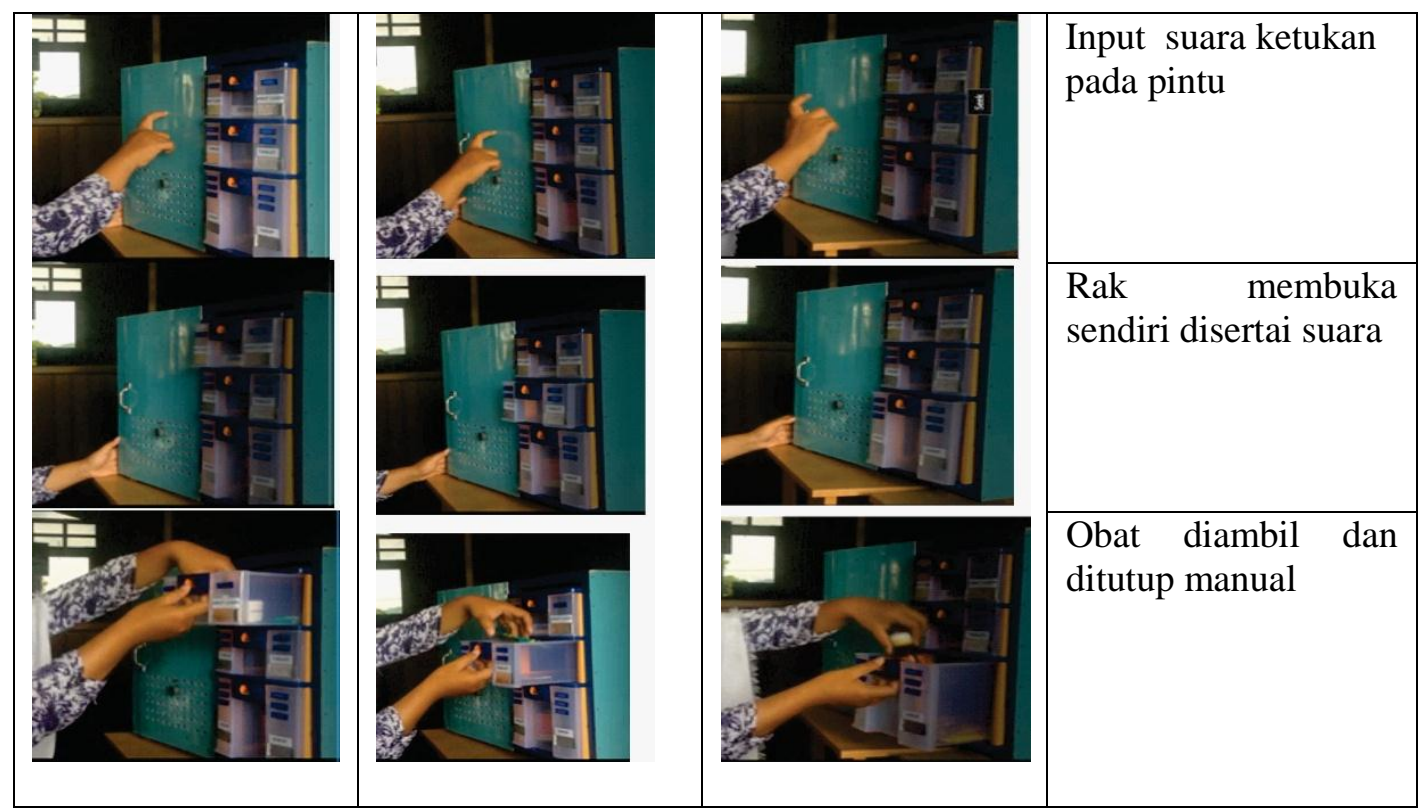

Gambar 8. proses pengambilan obat

\section{SIMPULAN}

Berdasarkan hasil tersebut di atas maka dapat disimpulkan :

1. Customer attribute desain kotak obat untuk tuna netra adalah aman dan paktis.

2. Desain parameter kotak obat untuk tuna netra adalah :

a. Ruangan kotak obat terdiri dari 1 ruang perangkat sistem otomatisasi 3 rak bertingkat penyimpan obat luar, obat tablet, obat sirup.

b. Bahan kotak obat merupakan kombinasi dari triplek melamin dan kayu (kotak luar); dan plastic polypropylene (ruang obat).

c. Ukuran total kotak obat: $50 \mathrm{~cm}$ x $30 \mathrm{~cm}$ x $40 \mathrm{~cm}$, ruang sistem otomatisasi : $30 \mathrm{~cm}$ x 30 $\mathrm{cm}$ x $40 \mathrm{~cm}$, ruang total tempat obat : $20 \mathrm{~cm} \times 30 \mathrm{~cm}$ x $40 \mathrm{~cm}$, rak atas: $20 \mathrm{~cm} \times 30 \mathrm{~cm} \times$ $10 \mathrm{~cm}$, rak tengah:20 xm x $30 \mathrm{~cm} \times 10 \mathrm{~cm}$, rak bawah:20 $\mathrm{cm} \times 30 \mathrm{~cm} \times 20 \mathrm{~cm}$.

d. Fungsi otomatisasi pintu berupa otomasi membuka rak dorong, input otomasi dengan suara ketukan pintu : 1 ketukan (obat luar); 2 ketukan (obat tablet); 3 ketukan (obat sirup), otomasi output suara jenis obat : obat luar, obat tablet, obat sirup.

e. Perangkat sistem otomatisasi terdiri dari sensor unit, modul microcontroller arduino, speaker, actuator switch solenoid, power supply 3 ampere 12 volt.

f. Ciri khusus penanda pintu kotak obat terdiri dari penanda akrilik (satu garis,dua garis, tiga garis), stiker huruf braile braile (luar, tablet, sirup), stiker huruf latin (obat luar, tablet, sirup).

3. Desain kotak obat dapat memenuhi kebutuhan pengguna.

Untuk penelitian lebih lanjut, pengembangan desain kotak obat masih perlu dilakukan, diantaranya penambahan otomatisasi penutup pintu dan penambahan rak agar jenis obat yang dibedakan menjadi lebih detail. 


\section{DAFTAR PUSTAKA}

Celik, M., \& Kahraman, C. (2009). Fuzzy axiomatic design-based Performance evolution model for docking facilities in shipbuilding industry : The case of Turkish shipyards. Expert Sistem with Application , 599-615.

El-Haik, B. S., \& Suh, N. P. (2005). Axiomatic Quality Integrating Axiomatic Design witk SixSigma, Reliability and Quality Engineering. New Jersey: John Willey \& Sons.

Fuente, J., \& Bix, L. (2010). User-Pack Interaction : Insight For Designing Inclusive ChildResistant Packaging. Journal of Inclusive Interaction Design.

Ferent, C., \& Doboli, A. (2013). An axiomatic model for concept structure description and its application to circuit design. Knowledge-Based Sistem Journal, 114-133.

Qiao, J., \& Shang, J. (2013). Application of axiomatic design method in in-pipe robot design. Robotics and Computer-Integrated Manufacturing, 49-57.

Sheskin, D. J. (2006). Handbook of Parametric and Non Parametric Statistical Procedures Third Edition. Washington: Chapman \& Hall/CRC

Suh, N. P. (2001). Axiomatic design ; Advance Application. New York: Pres, Inc.

Taha, Z., Soewardi, H., \& Dawal, S. Z. (2014). Axiomatic Design Principles in Analysing The Ergonomics Design Parameter of a Virtual Environtment. Interntional Journal of Industrial Ergonomics, 368-373.

Weeraranthe, C., \& Opatha, S. (2012). Challenges Faced By Visually Disabled People In Use Of Medicines, Self Adopted Coping Strategies And Medicine-Related Mishaps. WHO South East Asia Journal of Public Health, 256-267. 
